ORIGINAL ARTICLE

\title{
The practical application of reflectance spectrophotometry for the demonstration of haemoglobin and its degradation in bruises
}

\author{
V K Hughes, P S Ellis, T Burt, N E I Langlois
}

J Clin Pathol 2004;57:355-359. doi: 10.1136/jcp.2003.011445

See end of article for authors' affiliations

Correspondence to: Dr N Langlois,

Westmead Department of Forensic Medicine,

Mortuary, Level 1 ICP MR, Westmead Hospital, PO Box 533, Wentworthville, NSW 2145, Australia; neill@icpmr.wsahs.nsw. gov.au

Accepted for publication 5 November 2003
Aims: To develop a non-invasive method to demonstrate the presence of haemoglobin and its degradation products in bruises in live human subjects for the purposes of objectively assisting in the determination of the age of a bruise.

Methods: The cuvette holder unit of a Cary 100 Bio UV-Visible Spectrophotometer was replaced with the manufacture's fibre optic cable and optical reflectance probe. The probe was placed on the skin surface. The absorption spectrum from 780 to $380 \mathrm{~nm}$ was collected and transformed into the first derivative. Calculation of the first derivative permits absorption attributed to haemoglobin degradation (primarily to bilirubin, but also haemosiderin) to be separated from absorption by haemoglobin. First derivative and colorimetry values, expressed as CIEL*a*b data, were derived from scans of 50 bruises.

Results: The fibre optic cable and probe allowed the spectrophotometer to collect reproducible absorption spectra of bruises in the skin of living subjects. A bruise at three days has greater negative first derivative values at 480 and $490 \mathrm{~nm}$ than does a fresh bruise, indicating the local degradation of haemoglobin. Correlation between the first derivative and the CIEL* $a^{*} b$ " $b$ " values in a series of bruises indicates that the yellow colour in a bruise is proportional to the amount of local haemoglobin breakdown.

Conclusion: The ability to demonstrate the presence of haemoglobin and measure its degradation in bruises in living human subjects by a non-invasive method has not been described previously, and may be of use in the objective ageing of bruises for forensic purposes.
$\mathrm{B}$ $y$ visual inspection it may be possible to suggest that a bruise is either recent (fresh) or old (more than 18 hours), based on the presence or absence of yellow colour. $^{1-4}$ Such observations are by their very nature, subjective. In this regard, a recently published study indicates that there may be considerable differences in colour description of bruises between observers, who, as a result, may vary in their opinion regarding the age of a bruise. ${ }^{5}$ Estimation of the age of a bruise may be important to support or contradict testimony. ${ }^{6}$ Therefore, an objective method for assessing bruises is desirable and may assist with the determination of the age of a bruise.

A bruise (or contusion) represents a release of blood into the tissues, resulting from blunt force injury that does not cause a break in the skin. ${ }^{378}$ Thus, in the initial stages of a bruise, blood vessels are torn and blood escapes into the injured area. Once there has been a release of blood into the tissues there is an ensuing inflammatory reaction. During this process, macrophages are recruited to the injured area. ${ }^{10}$ Macrophages ingest red blood cells and metabolise the contained haemoglobin first to biliverdin and then rapidly to bilirubin. ${ }^{11}$ Therefore, during the healing of a bruise, both haemoglobin and bilirubin are present. The development of yellow colour in bruises has been attributed to the local production of bilirubin. ${ }^{12}$ Measuring the concentrations of haemoglobin and bilirubin in vivo may provide a method for assessing the age of a bruise.

\footnotetext{
"Potential contamination of the probe by organisms on the skin is prevented by interposing a sheet of overhead projection transparency acetate between the skin surface and the boss"
}

Investigations into the potential application of reflectance spectrophotometry for determining the age of bruises have been performed previously at the Department of Forensic Medicine, Dundee, UK under the direction of Professor D Pounder (DO Carson MSc thesis, University of Dundee, UK, 1998). However, this previous study could not reliably differentiate recent from old bruises. Our present paper describes a method for obtaining high quality, reproducible, surface reflectance spectra of bruises in the skin of a live human volunteer using the Cary 100 Bio Spectrophotometer with a fibre optic probe attachment. ${ }^{13}$ The reflectance scans can be transformed by the first derivative method into spectra that permit the identification of haemoglobin degradation products to differentiate recent from old bruises. ${ }^{14}$

The probe ${ }^{14}$ comprises a fibre optic coupler to replace the cuvette holder, a $2 \mathrm{~m}$ length of fibre optic cable, and a reflectance probe (diameter, $\sim 5 \mathrm{~mm}$ ), which is mounted within a metal boss (diameter, $\sim 30 \mathrm{~mm}$ ). In operation, the probe is slightly recessed within the centre of the boss (fig l). The use of the fibre optic cable provides the flexibility required to access bruises at awkward sites. Potential contamination of the probe by organisms on the skin is prevented by interposing a sheet of overhead projection transparency acetate between the skin surface and the boss. A "target" outline representing the boss is copied on to a $40 \times 40 \mathrm{~mm}$ square of acetate. The centre of the acetate is punched out to allow an unimpeded light path to the sample and to avoid reflection from the acetate interfering with the spectra collected. To obtain the measurement, the boss is separated from the bruised skin by the layer of acetate (fig 1). As the probe is recessed within the boss, it has no contact with the skin surface. However, it is necessary to darken the

Abbreviations: $\mathrm{ClE}$, Commission Internationale de l'Eclairage 
room, or shield the probe from incidental illumination, to prevent light in the room that is channelled through the acetate being recorded by the probe. Movement of the probe and fibre optic cable must be minimised to prevent inconsistent results. A fresh acetate sheet can be used for each subject, thereby eliminating any risk of cross infection between subjects.

Performing spectral derivatives allows the identification of small peaks in a large background signals. ${ }^{15}$ First, or higher order, derivatives are calculated by software supplied with the spectrophotometer. Derivative techniques calculate the slope and changes of slope of absorption spectra. ${ }^{14}{ }^{15}$ First order derivative spectra have been used to measure bilirubin in the presence of haemoglobin in solution by measuring the absorption at $480 \mathrm{~nm} \cdot{ }^{14}$ However, other work with derivatives suggests that measurements at $490 \mathrm{~nm}$ may be more discerning. ${ }^{16}$

The human eye detects colour using cones in the macula region of the retina. The cones contain pigment, which enable them to respond to light of certain wavelengths. In most people, there are three types of cones, which respond optimally to light in the red, green, and blue regions of the spectrum. Thus, any colour that can be perceived can be expressed using three simultaneous values quantifying the intensity of red, green, and blue light. Hence the RGB (red, green, blue) colour system utilised by most digital imaging equipment. However, colour can also be represented by alternative systems. Examples include the hue, saturation, and luminosity system and the Commission Internationale de l'Eclairage (CIE) system. In this colour system, designated CIEL*a*b, the " $b$ " value expresses the point along the yellowblue axis, the " $a$ " value corresponds to the green-red axis, and the "L" value is the luminosity. ${ }^{17-19}$ Colorimetry with production of CIEL*a*b values has been used to measure skin colour, ${ }^{2021}$ where it has been shown to be reliable and objective. ${ }^{22}$ Analysis of CIEL*a*b values has previously been applied to the study of hypostasis ${ }^{23} 24$ and bruises. ${ }^{25}$

\section{METHODS}

A Cary 100 Bio UV-visible spectrophotometer fitted with a Cary fibre optic couple and Cary fibre optic reflectance probe (Varian Australia Pty Ltd, Frenchs Forest, New South Wales, Australia) was used to obtain the spectra (purchase price AU\$ 22000 in October 2000). Zero and baseline corrections were used. The baseline was collected using a labsphere reflectance standard (Varian Australia Pty Ltd). The probe was placed on the standard with an interposing layer of acetate with the baseline/zero mode selected. The optimal

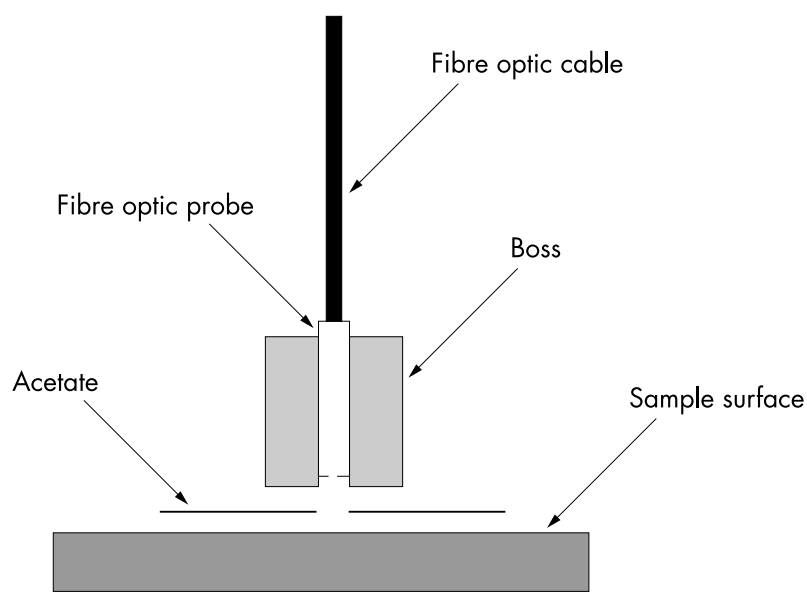

Figure 1 Schematic diagram of set up of Cary fibre optic probe using acetate separator. height of the probe within the boss was determined by finding the point of maximal light throughput using the Cary software. Then, the $100 \%$ reflectance baseline was recorded. To set the $0 \%$ baseline, the boss was placed on a closed black canister in which a hole permits light from the probe to enter the canister without reflection.

After baseline collection, the acetate target was placed on to the area of the skin to be examined. The boss containing the probe was then placed on to the acetate target, taking care to match up the perimeter of the probe with the perimeter photocopied on to the acetate (fig 1). Once the probe was in place, the absorption spectrum of the bruise was obtained over the range $780-380 \mathrm{~nm}$. A data interval of $1 \mathrm{~nm}$ was selected, with a signal averaging time of 0.2 seconds for each data point (resulting in a scan time of 70 seconds). Double beam mode was used with $2.6 \mathrm{Abs}$ of rear beam attenuation and the slit width was set to $3.0 \mathrm{~nm}$. It was necessary to darken the room while obtaining the spectra to prevent extraneous light travelling through the acetate being captured by the probe. It was also important to prevent the probe, or fibre optic cable, from moving during the capture of the spectrum because any movement can create background noise, compromising the reproducibility of the system.

A series of measurements was taken from the same site of a fresh bruise by leaving the acetate in place, but removing and reapplying the probe. Next, a series of areas was sampled within the same bruise. Finally, after three days, the bruise was scanned again. All scans were performed by the same operator. The first derivative of each scan was calculated using the spectral calculator of the CaryWin UV software (supplied by Varian Australia Pty Ltd with the Cary 100 Bio UV-visible spectrophotometer). A filter size of 9 and an interval of 3 were found to be optimal.

Fifty scans of bruises from live human volunteers were acquired (human research ethics committee approval reference HS/TG HREC2002/5/4.6(1432)). All the bruises had been acquired in normal daily activities and only bruises on the arms or legs were studied. The age of the bruise was ascertained by asking the volunteer and only bruises for which the volunteer could accurately pinpoint the time of injury were used. Colorimetry values were calculated using the Cary Win UV color application, 85-101684-00 version 2.00(15) supplied by Star-tek (Victoria, Australia). CIEL*a*b values were calculated based over a scan range of 780$380 \mathrm{~nm}$ using a $1 \mathrm{~nm}$ data interval. Correction was performed using the zero and baselines of the scans. Results were based on a D65 illuminant with an observer angle of $2^{\circ}$. Colour matching or colour correction were not used. Using the software package, a negative value indicated more yellowness.

Statistical analysis was performed using Statview version 4.5 (Abacus Concepts Inc, Berkeley, California, USA).

\section{RESULTS}

The series of scans taken by repeated applications of the probe to the same area of the bruise showed excellent reproducibility (fig 2). The expected absorption peaks of haemoglobin at $576 \mathrm{~nm}, 543 \mathrm{~nm}$, and in the range 414$422 \mathrm{~nm}$ were present. ${ }^{26}$ The absorption range is just over 1 Abs.

Scans taken from different areas in the fresh bruise (fig 3) show a greater degree of variability. However, when the first derivatives of these scans are produced (fig 4), it can be seen that the variability of the baseline is removed and that the curves are roughly confluent over the range $510-470 \mathrm{~nm}$. On the first derivative scans, the magnitude at $480 \mathrm{~nm}$ ranges from 0.0 to $-0.00128 \mathrm{Abs} / \mathrm{nm}$. At $490 \mathrm{~nm}$, the magnitude ranges from +0.00050 to $-0.00021 \mathrm{Abs} / \mathrm{nm}$. 


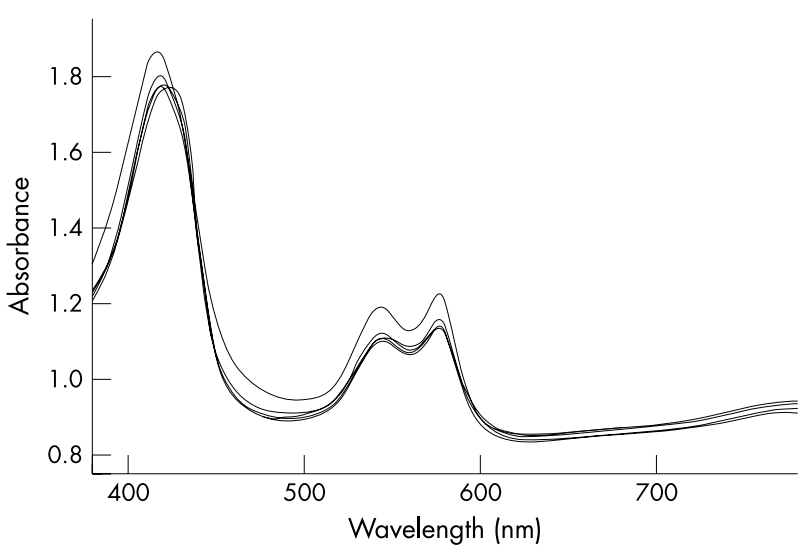

Figure 2 Scans of fresh bruise (less than six hours old): five consecutive scans of the same area.

Spectra of the bruises three days later again showed variation between areas sampled (fig 5). Absorption peaks caused by haemoglobin are still present, but are reduced in intensity. There is a new slope over the region $510-470 \mathrm{~nm}$. There is no perceptible absorbance peak in the range 660$620 \mathrm{~nm}$. The first derivatives again reduce the differences between the scans (fig 6). In the first derivative scans, the absorption at $480 \mathrm{~nm}$ ranges from -0.00193 to $-0.00237 \mathrm{Abs} /$ $\mathrm{nm}$. At $490 \mathrm{~nm}$, the absorption ranges from -0.00151 to $-0.00205 \mathrm{Abs} / \mathrm{nm}$. The first derivatives show no evidence of absorption as a result of biliverdin because there are no peaks in the range $660-620 \mathrm{~nm}$.

The 50 bruise scans were acquired from 27 bruises taken from 25 volunteers (two volunteers presented on two separate occasions with bruises). The age range of the subjects was from 22 to 63 years (mean, 37.5; median, 36). The sites of the bruises were: upper arm, eight; lower arm, four; hand, five; upper leg, two; lower leg, eight. Two bruises were scanned four times, four were scanned three times, nine were scanned twice, and 12 were scanned on one occasion only. The " $\mathrm{b}$ " colorimetry value of 50 bruises ranging from 1 to 378 hours old (median, 95) varied from -3.73 to -0.77 (median, -1.3 ). The first derivative values at $490 \mathrm{~nm}$ ranged from -0.06 to $-0.0002 \mathrm{Abs} / \mathrm{nm}$ (median, -0.001 ), and the first derivative values at $480 \mathrm{~nm}$ ranged from -0.07 to $-0.0002 \mathrm{Abs} / \mathrm{nm}$ (median, -0.002). A correlation analysis revealed that an increasing negative first derivative value at $490 \mathrm{~nm}$ corresponded to a more negative (yellow) " $\mathrm{b}$ " value (coefficient of correlation $^{2}=0.78$; fig 7). The correlation of the first derivative value at $480 \mathrm{~nm}$ was not so good (coefficient of correlation ${ }^{2}=0.72$ ).

\section{DISCUSSION}

Reflectance spectrophotometry has previously been used to study the pigments and colour of living human skin. ${ }^{27}$ For example, this method has been used to estimate the melanin density in white individuals to determine an individual's susceptibility to epidermal tumours. ${ }^{28}$ The technique has also been used in the assessment of wound healing. ${ }^{29}$ In addition, it has previously been used to study bruises (DO Carson MSc thesis, University of Dundee, UK, 1998); however, in that study, although reflectance spectroscopy was sufficiently sensitive to identify the presence of haemoglobin in a bruised area, it was unable to identify haemoglobin degradation products. Our present study shows that reproducible readings can be obtained from one point within a bruise (fig 2). However, as would be expected, there is variation between different areas within a bruise (fig 3 ). This variability makes comparison between bruises difficult and could mask the

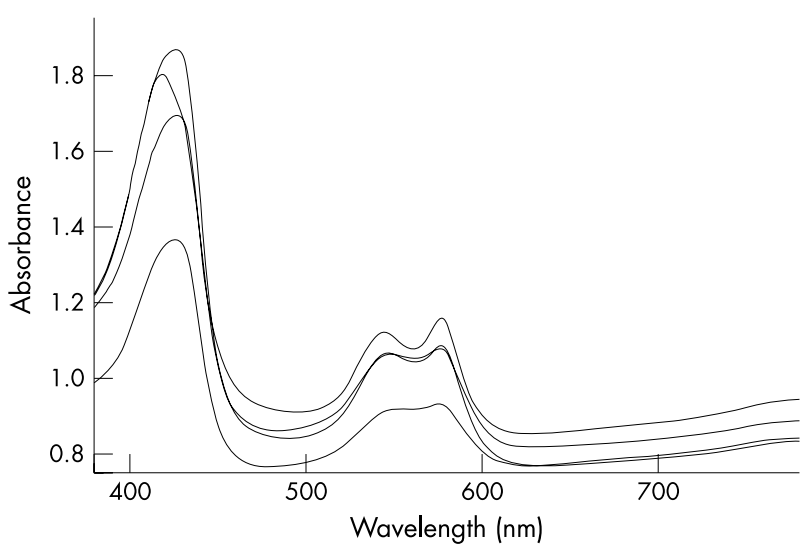

Figure 3 Scans of fresh bruise (less than six hours old): four different areas.

presence of degradation products of haemoglobin. This problem can be overcome by obtaining first derivatives of the scans.

The first derivative method calculates the slope of the scan. The first derivative of a rapidly rising line is a large positive value. For a gentle downward sloping line it is a small negative value. The first derivative of a flat line is zero. Therefore, for the region of the spectrum of haemoglobin from 510 to $470 \mathrm{~nm}$, where the spectrum is almost level (fig 3 ), the first derivative is around zero (fig 4). Bilirubin has a broad absorption peak at $460 \mathrm{~nm} .{ }^{14}{ }^{30}$ Thus, superimposition of the descending side of the bilirubin curve on the flat region of the haemoglobin spectrum results in a negative first derivative value in the range $510-470 \mathrm{~nm}$. Previously published work using the first derivative method to measure bilirubin in the presence of haemoglobin used the first derivative value at $490 \mathrm{~nm}$ and at $480 \mathrm{~nm} .{ }^{31}$ We found that the measurement of the first derivative value at $490 \mathrm{~nm}$ shows more change than the value at $480 \mathrm{~nm}$ so that $490 \mathrm{~nm}$ is better for discriminating between fresh bruises and three day old bruises (fig 6).

The first derivative method also has the advantage of reducing the difference between scans where there is a difference in baseline offsets. This is seen in fig 4, where there is near confluence of the lines in the range $510-470 \mathrm{~nm}$, and where all the original curves (fig 3) are flat, but have different baseline offsets. There is less confluence in the same region in fig 6 , which is attributed to heterogeneity of bilirubin distribution within the bruise.

\section{"We found that the measurement of the first derivative value at $490 \mathrm{~nm}$ shows more change than the value at $480 \mathrm{~nm}$ so that $490 \mathrm{~nm}$ is better for discriminating between fresh bruises and three day old bruises"}

We had previously determined, using a Kodak colour separation guide (cat 152 7654), that there was an excellent, but negative, correlation between Adobe Photoshop (version 6.0 for Macintosh, Adobe Systems Ltd) CIEL*a*b " $b$ " values derived from image analysis of a photograph and the colorimetry " $\mathrm{b}$ " values obtained by directly scanning the colour reference card (coefficient of correlation $^{2}=0.92$; results not shown). The correlation between the first derivative values at 490 and $480 \mathrm{~nm}$ are consistent with the suggestion that greater amounts of bilirubin correspond to increasing yellow colour in a bruise. ${ }^{12} 3233$ The coefficient of correlation was better for the $490 \mathrm{~nm}$ values than for the $480 \mathrm{~nm}$ values, suggesting 


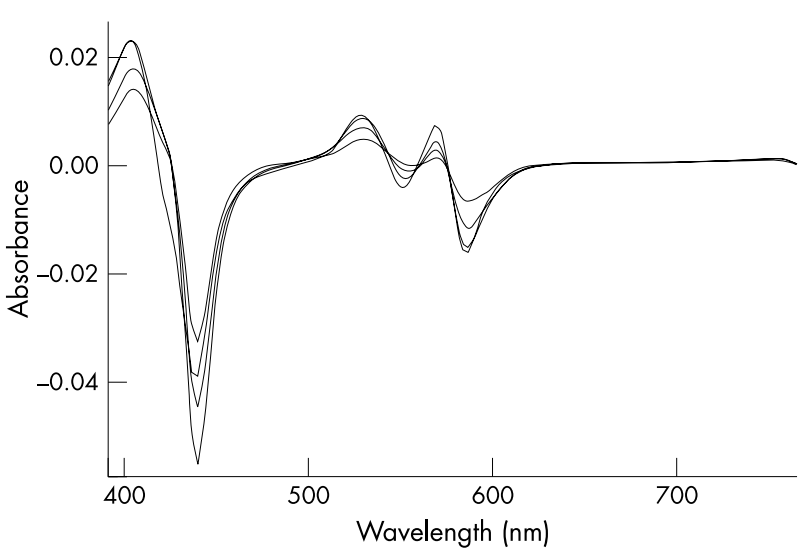

Figure 4 First derivatives from scans in fig 3.

that the $490 \mathrm{~nm}$ first derivative value would have a greater potential for use in the determination of the age of a bruise.

Haemoglobin is metabolised by haemoxygenase to biliverdin. ${ }^{34-36}$ Biliverdin has an absorption peak in the range 660 $620 \mathrm{~nm} \cdot{ }^{37}$ It would be expected that it would not be possible to detect the presence of biliverdin, because it has been shown that it is rapidly metabolised to bilirubin by biliverdin reductase ${ }^{34-36}$ There is no discernable peak in the range $660-$ $620 \mathrm{~nm}$ in the three day old bruises in the native (fig 5) or in the first derivative scans (fig 6), which is consistent with biliverdin being short lived.

It was found that the acetate could allow surrounding light to reach the probe, by acting as a light channel. Although this could be avoided by using a blackened acetate sheet, reduction of ambient light was found to be sufficient to avoid this problem. The fibre optic probe is extremely sensitive to movement, with any movement producing noise on the scan. Therefore, it is essential that the probe is held steady. It must be noted that the probe records only surface refection and will only capture the results of biological processes near the surface of the skin.

With the above methodology, using the spectrophotometer and the supplied software to derive the first derivatives, it is possible to produce scans that can differentiate between new and old bruises. Furthermore, the results are consistent with the suggestion that the yellow colour in an old bruise correlates with the presence of bilirubin. ${ }^{12}{ }^{33}$ However, at least some of the yellow colour may also be attributable to the local formation of haemosiderin. The local formation of haemosiderin within a bruise is well documented. ${ }^{9}{ }^{10}{ }^{38}$ Haemosiderin

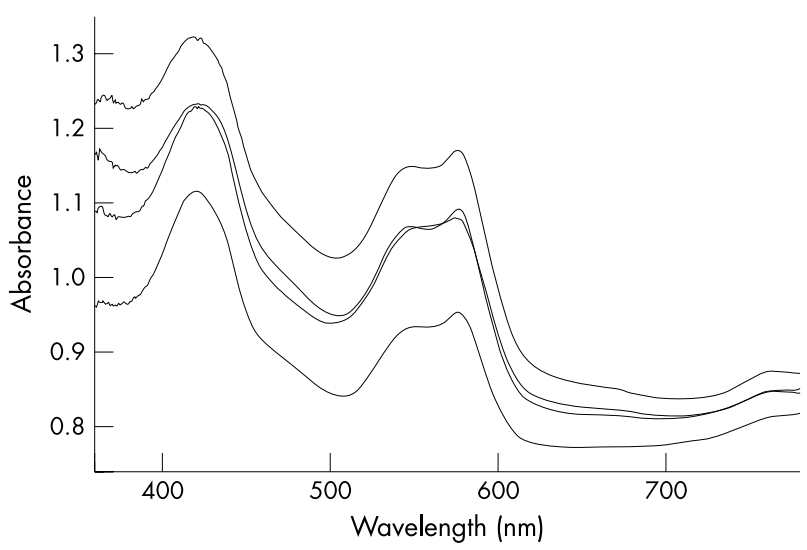

Figure 5 Scans from old bruise (three days): four different areas.

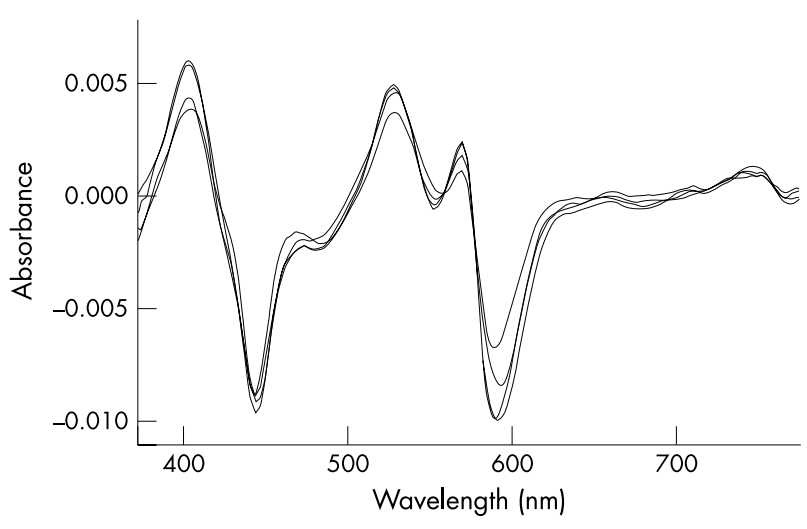

Figure 6 First derivatives from scans in fig 5.

has been described as having a brown colour in the tissue, but by using the Perl's staining method, it appears blue. ${ }^{39}$ Haemosiderin is formed when the iron that is released by the degradation of haemoglobin is complexed with protein (mostly ferritin). Its atomic structure (determined by $x$ ray diffraction pattern analysis and electron microscopy) is indistinguishable from ferritin, and it appears that haemosiderin comprises an aggregate of ferritin particles that have undergone partial proteolysis. ${ }^{114041}$ The ultraviolet to visible absorption spectra of ferritin and haemosiderin show increasing absorption from long to short wavelengths, with no specific peaks. ${ }^{42}{ }^{43}$ Any superimposition of absorption as a result of haemosiderin over the spectra of haemoglobin and bilirubin would increase the negative value of the slope from 470 to $510 \mathrm{~nm}$ (where the absorption by haemoglobin is flat and the absorption of bilirubin is declining ${ }^{14}$ ). Therefore, the presence of haemosiderin would increase the negative value of the first derivative at 480 or $490 \mathrm{~nm}$, and it is not possible to distinguish absorption as a result of haemosiderin from that of bilirubin. Thus, the yellow colour in a bruise is attributed to the formation of local breakdown products of haemoglobin, with the spectroscopic measurement of absorption at 480 or $490 \mathrm{~nm}$ being predominantly attributed to bilirubin (because it shows the greater rate of change over that range).

The ability simultaneously to demonstrate the presence of haemoglobin and measure its degradation, revealing a correlation between local haemoglobin degradation and the formation of yellow colour in bruises in living human subjects by a non-invasive method, has not been described previously. Studies are being performed to test the applicability

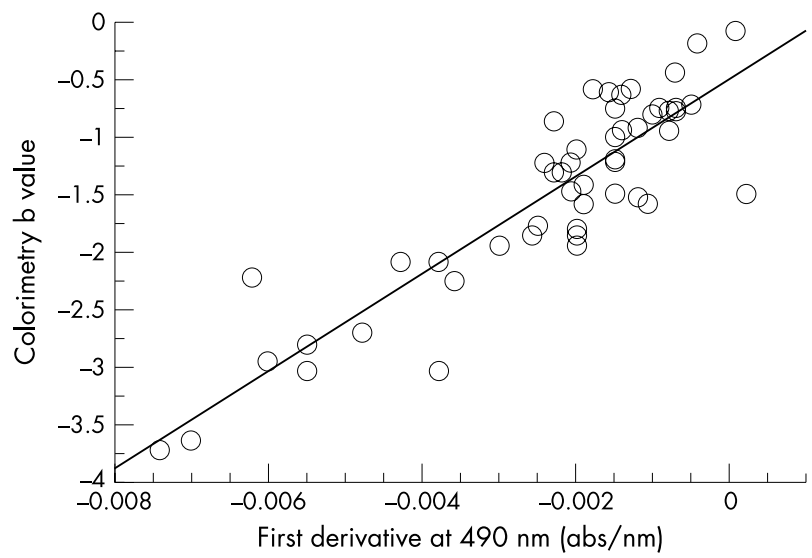

Figure 7 Correlation between colorimetry " $b$ " values and first derivatives at $490 \mathrm{~nm}$ in 50 bruises. 


\section{Take home messages}

- For the first time, we have used non-invasive reflectance spectrophotometry to demonstrate the presence of haemoglobin and measure its degradation in bruises in living human subjects

- This method may be of use in the objective ageing of bruises for forensic purposes

- It may be possible to extend the use of this method to bruises in cadavers, but further research is necessary

of this technique to the ageing of bruises. Specifically, a large study is in progress to acquire a sufficient number of volunteers to investigate issues such as: whether body location exerts an effect, the effect of skin colour, whether all bruises with a bilirubin spectrum appear yellow, calculation of sensitivity and specificity data, whether naked eye detection is better than spectrophotometry, and the effect of the size of the bruise or other variables. Work is also in progress to assess the application of this method to bruises in cadavers and to compare the spectrophotometry results with histology. It is also intended to investigate the effects of lividity and decomposition.

Our study has shown that, as would be predicted, biliverdin does not accumulate, ${ }^{34-36}$ and that the yellow colour that develops in a bruise can be attributed to the local degradation of haemoglobin. Given that it takes time for macrophages to accumulate ${ }^{98}$ and metabolise haemoglobin, ${ }^{11}$ this would account for the previously reported delay before a yellow colour is apparent in a bruise. ${ }^{4}$

\section{ACKNOWLEDGEMENTS}

The authors would like to thank The Charitable Trustees and the staff specialists of Western Sydney Area Health Authority for their generous grant that enabled the purchase of the Cary 100 Bio UVvisible spectrophotometer and S Evans of Varian Australia for his technical support.

\section{Authors' affiliations}

V K Hughes, P S Ellis, N E I Langlois, University of Sydney, Westmead Department of Forensic Medicine, PO Box 533, Wentworthville, NSW 2145, Australia

T Burt, Varian Australia Pty Ltd, 679 Springvale Road, Mulgrave, Victoria, Vic 3170, Australia

This work was presented at the Australian Coroner's Conference 2002, Manly, Australia.

\section{REFERENCES}

1 DiMaio VJ, DiMaio D. Forensic pathology, 2nd ed. New York: CRC Press, 2001.

2 Knight B. Forensic pathology, 2nd ed. London: Arnold, 1998.

3 Davis GJ. Patterns of injury. Blunt and sharp. Clin Lab Med 1998;18:339-50.

4 Langlois NEI, Gresham GA. The ageing of bruises: a review and study of the colour changes with time. Forensic Sci Int 1991:50:227-38.

5 Munang LA, Leonard PA, Mok JYQ. Lack of agreement on color description between clinicians examining childhood bruising. Journal of Clinical Forensic Medicine 2002;9:171-4

6 Schwartz AJ, Ricci LR. How accurately can bruises be aged in abused children? Literature review and synthesis. Pediatrics 1996:97:254-6.

7 Capper $\mathrm{C}$. The language of forensic medicine: the meaning of some terms employed. Med Sci Law 2001;451:256-9.

8 Spilsbury B. The medico-legal significance of bruises. Medico Legal and Criminal Review 1937;7:215-27.
9 Thornton RN, Jolly RD. The objective interpretation of histopathological data: an application to the ageing of ovine bruises. Forensic Sci Int 1986;31:225-39.

10 McCausland IP, Dougherty R. Histological ageing of bruises in lambs and calves. Aust Vet J 1978:54:525-7.

11 Muir R, Niven JSF. The local formation of blood pigments. J Pathol 1935;41:183-97

12 Hamdy MK, May KN, Powers JJ. Some physical and physiological factors affecting poultry bruises. Poult Sci 1961;40:790-5.

13 Fyfe D. Measurement of human skin fluorescence using fibre optics and the Cary Eclipse. Victoria, Australia: Varian Australia Pty Ltd, Report No 5 August, 1998.

14 Amazon K, Soloni F, Rywlin AM. Separation of bilirubin from hemoglobin by recording derivative spectrophotometry. Am J Clin Pathol 1981;75:519-23.

15 Skujins S. Part I. A review of areas of application and the basic principles of the derivative technique. Steinhauserstrasse, Zug: Varian Australia Pty Ltd, 1986 April 1986. Report No UV-31.

16 Edwards EA, Duntley SQ. The pigments and color of living human skin. Am J Anat 1939;65:1-33.

17 Wyszecki G, Stiles WS. Color science. Concepts and methods, quantitative data and formula, 2nd ed. New York: John Wiley and Sons, 1982.

18 CIE. The relationship between digital and colorimetric data for computercontrolled CRT displays. Vienna: CIE, 1996

19 Billmeyer FW. Survey of color order systems. Color Res Appl 1987; 12:173-86.

20 Andreassi L, Casini L, Simoni S, et al. Measurement of cutaneous colour and assessment of skin type. Photodermatol Photoimmunol Photomed 1990;7:20-4.

21 Weatherall IL, Coombs BD. Skin color measurements in terms of CIELAB color space values. J Invest Dermatol 1992:99:468-73.

22 Trujillo O, Vanezis P, Cermignani M. Photometric assessment of skin colour and lightness using a tristimulus colorimeter: reliability of inter and intrainvestigator observations in healthy adult volunteers. Forensic Sci In 1996;81:1-10.

23 Vanezis P. Assessing hypostasis by colorimetry. Forensic Sci Int 1991;52:1-3.

24 Vanezis $\mathbf{P}$, Trujillo $O$. Evaluation of hypostasis using a colorimeter measuring system and its application to assessment of the post-mortem interval (time of deaths). Forensic Sci Int 1996:78:19-28.

25 Vanezis P. Interpreting bruises at necropsy. J Clin Pathol 2001;54:348-55.

26 Makarem A. Hemoglobins, myoglobins and haptoglobins. In: Henry RJ, Cannon DC, Winkelman JW, eds. Clinical chemistry principles and techniques, 1st ed. Maryland: Harper and Row, 1974:1111-214.

27 Edwards P, Roberts I, Clarke $M$, et al. Increasing response rates to postal questionnaires: systematic review. BMJ 2002;324:1183-5.

28 Dwyer T, Muller HK, Blizzard L, et al. The use of spectrophotometry to estimate melanin density in humans. Cancer Epidemiol Biomarkers Prev 1998;7:203-6

29 Schmidt WD, Liebold K, Fassler D, et al. Contact-free spectroscopy of leg ulcers: principle, technique, and calculation of spectroscopic wound scores. J Invest Dermatol 2001;1 16:531-5.

30 Merrick MF, Pardue HL. Evaluation of absorption and first- and secondderivative spectra for simultaneous quantification of bilirubin and hemoglobin. Clin Chem 1986;32:598-602.

31 Barbet JP, Houette A, Durigon M. Histological assessment of gestational age in human embryos and fetuses. Am J Forensic Med Pathol 1988;9:40-4.

32 Lemberg R, Wyndham RA. Reduction of biliverdin to bilirubin in tissues. Biochem J 1936:30:1147-70.

33 Otterbein LE, Choi AMK. Heme oxygenase: colors of defense against cellular stress. Am J Physiol 2000;279:L1029-L37.

34 Pimstone NR, Tenhunen R, Seitz PT, et al. The enzymatic degradation of hemoglobin to bile pigments by macrophages. J Exp Med $1971 ; 133: 1264-81$.

35 Tenhunen R. The enzymatic degradation of heme. Semin Hematol 1972;9:19-29

36 Maines MD, Cohn J. Bile pigment formation by skin heme oxygenase: studies on the response of the enzyme to heme compounds and issue injury. J Exp Med 1977; 145:1054-9.

37 Larson EA, Evans GT, Watson C. A study of the serum biliverdin concentration in various types of jaundice. J Lab Clin Med 1947;32:481-8.

38 Betz P. Histological and enzyme histochemical parameters for the age estimation of human skin wounds. Int J Legal Med 1994;107:60-8.

39 Bancroft JD, Stevens A. Theory and practice of histological techniques, 4th ed. Hong Kong: Churchill Livingstone, 1996.

40 Ritcher GW. The iron-loaded cell-the cytopathology of iron storage. Am J Pathol 1978;91:363-415.

41 Fischbach FA, Gregory DW, Harrison PM, et al. On the structure of hemosiderin and its relationship to ferritin. J Ultrastructure Res 1971;37:495-503.

42 May ME, Fish WW. The UV and visible spectral properties of ferritin. Arch Biochem Biophys 1978;190:720-5.

43 Wells CL, Wolken JJ. Microspectrophotometry of haemosiderin granules. Nature 1962;193:977-8. 


\section{PostScript}

\section{CORRESPONDENCE}

If you have a burning desire to respond to a paper published in the Journal of Clinical Pathology, why not make use of our "rapid response" option?

Log on to our website (www.jclinpath. com), find the paper that interests you, and send your response via email by clicking on the "eletters" option in the box at the top right hand corner.

Providing it isn't libellous or obscene, it will be posted within seven days. You can retrieve it by clicking on "read eletters" on our homepage.

The editors will decide as before whether to also publish it in a future paper issue.

\section{Secretory carcinoma of the male breast}

Breast carcinomas in men account for $<1 \%$ of all subtypes and most belong to the infiltrating duct variety of the "not otherwise specified" type. ${ }^{1}$ To date, only 15 cases of the rare subtype of secretory carcinoma have been reported in men. ${ }^{2}$ The youngest patient was a 6 year old boy ${ }^{3}$ and oldest a 66 year old man. ${ }^{4}$ We present a case of secretory carcinoma in a 19 year old man whose tumour cells were vimentin positive and oestrogen and progesterone receptor negative.

The patient presented to a private clinic in rural Northern India with a painful, rapidly progressing lump in the right breast of two

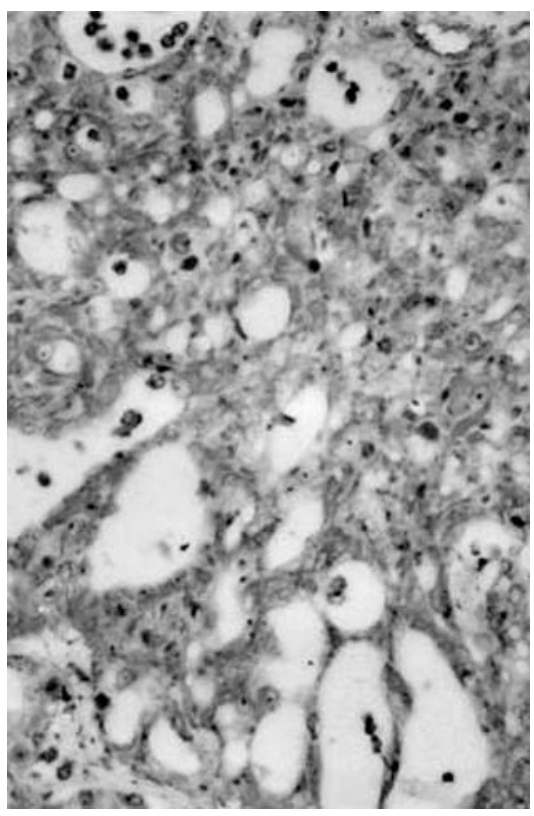

Figure 1 Low power view of tumour cells arranged in a microcystic pattern.

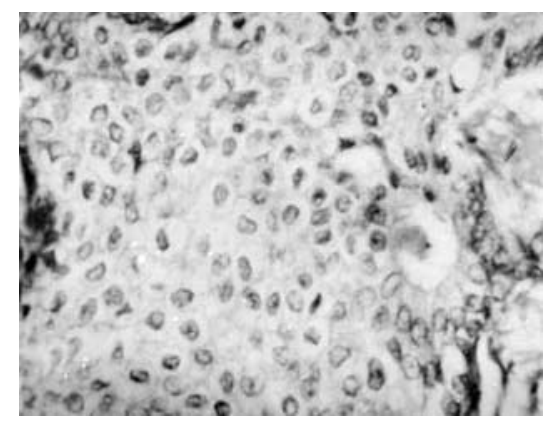

Figure 2 High power view of polygonal tumour cells with abundant pale to clear cytoplasm and focal intraluminal secretions.

years duration. A lumpectomy was performed at a local hospital. Three months after surgery, two small lumps reappeared on the right chest wall, which were excised and sent to our hospital for histopathology. Two nodules measuring $4 \times 2 \times 2 \mathrm{~cm}$ and $2 \times 2 \times 2 \mathrm{~cm}$ were received. Cut sections were greyish yellow and densely fibrous.

Microsections showed an infiltrating tumour with tumour cells arranged in microcystic and cribriform patterns separated by scant fibroconnective stroma (fig 1). The tumour cells were round to polygonal with abundant pale to clear amphophilic cytoplasm. The nuclei were large and central with stippled chromatin (fig 2). Pink amphophilic secretions were seen in the lumina of microcysts (fig 2) and focally within the cells. The intracellular and extracellular secretions were periodic acid Schiff (diastase resistant) and mucicarmine positive. Immunohistochemistry for the oestrogen receptor (ER ID5; Immunotech, Marseille, France), progesterone receptor (PR 105; Immunotech), and vimentin (Dako, Glostrup, Denmark) was performed. The tumour cells were universally oestrogen receptor and progesterone receptor negative, but were vimentin positive (100\% positivity).

Mc Diwitt and Stewart first described breast tumours in children with a favourable prognosis (1966) and named them juvenile carcinomas. ${ }^{5}$ This was later replaced by the term secretory carcinoma by Tavassoli. ${ }^{5}$ De Bree et al have recently reviewed secretory carcinoma in men and reported a median age of 17 years, with the tumour size ranging from 1.2 to $4 \mathrm{~cm}^{2}$. They also noticed that lymph node metastases were frequent in tumours less than $2 \mathrm{~cm}$, unlike secretory carcinomas in women. Hence, secretory carcinomas in men appear to be more aggressive. ${ }^{2}$ The tumour in our patient was also an aggressive one because an early recurrence was seen.

Very few authors have performed immunohistochemical studies on secretory carcinomas of male breasts. ${ }^{3}$ These tumours are said to be epithelial membrane antigen, cytokeratin, carcinoembryonic antigen (polyclonal), S-100, and $\alpha$ lactalbumin positive.

Although traditionally vimentin expression has been associated with mesenchyme and mesenchymal tumours, many epithelial malignancies are vimentin positive, including those of the breast. ${ }^{6}$ Vimentin expression has been studied extensively in female breast tumours (predominantly in infiltrating ductal carcinomas) and is associated with biological aggressiveness. ${ }^{6}$ The role of vimentin positivity in male breast carcinomas needs to be explored. It is unclear whether vimentin positivity in our case is related to the aggressiveness of the tumour and larger studies are needed to investigate this possibility.

S R Niveditha, P Bajaj, A Nangia Department of Pathology, Lady Hardinge Medical College, Smt. Sucheta Kriplani and Kalawati Saran Hospitals, New Delhi 110001 , India; srniveditha@hotmail.com

\section{References}

1 Rosen PP. Breast lesions in men and children. In: Rosen PP, ed. Breast pathology-diagnosis by needle core biopsy. Philadelphia: Lippincott Williams and Wilkins, 1999:263-6.

2 De Bree E, Askoxylakis J, Giannikaki E, et al. Secretory carcinoma of the male breast. Ann Surg Oncol 2002;9:663-7.

3 Rosen PP. Secretory carcinoma. In: Rosen PP, ed. Breast pathology-diagnosis by needle core biopsy. Lippincott Williams and Wilkins, 1999: 183-4

4 Kerwabera H, Yamana M, Okoda S. Secretory carcinoma in a 66 year old man. J Clin Pathol 1998;57:545-7

5 Tavassoli FA. Infiltrating carcinoma, special types. In: Tavassoli FA, ed. Pathology of the breast. New York: Elsevier Science, 1992:384-8.

6 Santini D, Ceccarelli C, Taffurelli M, et al. Differentiation pathways in primary invasive breast carcinoma as suggested by intermediate filament and biopathological marker expression. J Pathol 1996;179:386-91.

\section{Gastric intestinal metaplasia}

We read with interest the article by DinisRibeiro et al concerning a follow up model for patients with atrophic gastritis and intestinal metaplasia (IM). ${ }^{1}$ The model proposed is based on "a minimum of two endoscopic biopsies", although $40 \%$ of patients had at least three biopsies, and more than $15 \%$ of patients had more than four biopsies performed. Within that setting, the authors investigated the significance of type I, II, and III IM, and concluded that those with type I IM should have a less intensive follow up protocol, whereas in those with type III IM, "a hunt for high grade neoplasia should be performed".

In previous publications, several authors have reported that IM may be detected in biopsies taken exclusively from endoscopically abnormal areas, ${ }^{2}$ whereas others recommended that gastric biopsies should be harvested from pre-established mucosal sites. $^{3}$ In this respect, the Sydney system ${ }^{3}$ for grading of gastritis has provided practical guidelines for optimal biopsy sampling of the gastric mucosa. Notwithstanding, using the Sydney system's recommendations, ElZimaity and Graham $^{4}$ found that IM was missed in more than $50 \%$ of the biopsies from "Sydney" sites in patients with confirmed gastric IM on multiple site sampling. These authors concluded that the minimum 
number of biopsies needed to identify IM should probably be eight, ${ }^{4}$ and emphasised that current and future studies that use the Sydney system as a basis for detecting gastric IM are not likely to be reliable. Thus, it appears that sampling gastric biopsies from pre-established mucosal sites, ${ }^{2}$ or from endoscopically abnormal areas ${ }^{3}$ may be both insufficient to calculate IM prevalence figures, and inadequate to estimate the possible risk of gastric IM in long follow up studies. ${ }^{4}$

By assessing IM at low power $(\times 4)$ examination, we found in histological sections from gastrectomy specimens that IM could be either spotty or extended (encompassing one or more entire low power microscopic field/section). ${ }^{5}$ When extended IM was present in $\geqslant 5$ histological sections, IM was considered to be widespread. Thus, IM may be spotty, or extended and widely distributed. Against that background, the proposal of Dinis-Ribeiro et al of obtaining two or three biopsies (in most of their series) as representative for the state of the gastric mucosa appears highly unsatisfactory. Moreover, several authors have been unable to corroborate the prognostic significance of incomplete IM type III. $^{67}$ Kato et al found that incomplete IM usually occurs in the antrum, whereas complete IM is usually seen in the fundus. ${ }^{7}$

The article by Dinis-Ribeiro et al points out that two pathologists reviewed all the slides, and that "agreement was achieved in $85 \%$ of the cases. In case of disagreement, a consensus was obtained...". Because no mention is made regarding double blind examination with coated slides, we assume that the authors did not carry out that procedure. The possibility of intraobserver and of interobserver variations was not explored.

According to Dinis-Ribeiro “...endoscopic examination throughout the entire gastric cavity may still fail to diagnosis dysplasia and cancer". The authors forgot to include areas with IM, particularly when chromography of the gastric mucosa is not performed. That procedure was not mentioned in the list of "methods" used in their follow up studies.

C A Rubio, R Befrits Department of Pathology and Gastroenterology,
arolinska Institute and Hospital, 17176 Stockholm, Karolinska Institute and Hospital, 17176 Stockholm,
Sweden; Carlos.Rubio@onkpat.ki.se

\section{References}

1 Dinis-Ribeiro M, Lopes C, da Costa-Pereira A, et al. A follow up model for patients with atrophic chronic gastritis and intestinal metaplasia. J Clin Pathol 2004:57:177-82.

2 Whiting J, Sigurdsson A, Rowlands D, et al. The long term results of endoscopic surveillance of premalignant gastric lesions. Gut 2002:50:378-81.

3 Misiewicz J, Tygat G, Goodwin C, et al. The Sydney system: a new classification of gastritis. Working Party Reports 1990:1-10.

4 El-Zimaity H, Graham D. Evaluation of gastric biopsy site and number of identification of $\mathrm{H}$ pylori or intestinal metaplasia. The role of Sydney system. Hum Pathol 1999;30:72-7.

5 Rubio CA, Hirota T, Itabashi T, et al. Extended intestinal metaplasia. A survey in 1392 gastrectomies from dwellers of the Pacific basin. Anticancer Res [In press.]

6 Rameshar K, Danders D, Hopwwood D. Limited value of type III intestinal metaplasia in predicting risk of gastric carcinoma. J Clin Pathol 1987;40:1287-90.

7 Kato Y, Kitagawa T, Yanagisawa A, et al. Site-dependent development of complete and incomplete intestinal metaplasia types in the human stomach. Jpn J Cancer Res 1992;83:178-83.

\section{CALENDAR OF EVENTS}

Full details of events to be included should be sent to Maggie Butler, Technical Editor JCP, The Cedars, 36 Queen Street, Castle Hedingham, Essex CO9 3HA, UK; email: maggie.butler2@btopenworld.com

\section{ACP Management Course for Pathologists, 2004}

8-10 September 2004, Hardwick Hall Hotel, Sedgefield, County Durham, UK

Further details: V Wood, ACP Central Office, 189 Dyke Road, Hove, East Sussex BN3 ITL, UK. (Tel: +44 (0) 1273 775700; Fax: +44 (0) 1273 773303; Email: Jacqui@pathologists. org.uk)

\section{Combined Adult and Congenital Cardiovascular Pathology Course}

8-10 November 2004, Imperial School of Medicine, National Heart and Lung Institute, London, UK

Further details: Short Course Office, National Heart and Lung Institute, Dovehouse Street, London SW3 6LY, UK. (Tel: +44 (0)20 7351 8172; Fax: +44 (0)20 7351 8246; Email: shourtcourse.NHLI@IC.AC.UK)

\section{Asian Pacific Association for Study of the Liver Biennial Conference}

11-15 December 2004, New Delhi, India

Further details: Dr V Malhotra (General Secretary) or Dr P Sakhuja (Treasurer and Pathology Coordinator), Room 325, Academic Block, Department of Pathology, GB Pant Hospital, New Delhi 110002, India. (Tel: +91 11 23237455; Email: welcome@apaslindia2004. com; Website: www.apaslinzdia2004.com)

\section{BOOK REVIEWS}

\section{Atlas of Diagnostic Cytopathology: Second Edition}

Edited by B F Atkinson. Published by Saunders, 2003 , £156.00, pp 856. ISBN 07121600638

Those who are interested in cytology, at all levels of experience, are notoriously fond of atlases. The neophyte nourishes a belief that a set of images and (relatively) brief text will quickly lead to competence, whereas the expert hopes that there will be help with a difficult diagnostic problem, or the aesthetic enjoyment of images more beautiful than any in their experience. The "Atlas of Diagnostic Cytopathology" (second edition) edited by Barbara F Atkinson alludes to these disparate audiences in the preface, stating that the work is for "cytopathology residents, fellows, cytotechnology students, and ....experienced cytopathologists". The first two categories are likely to judge a book by its brevity and clarity, and the last by comparison with their favourites of the genre, such as the works of Orell, DeMay, or Lopes Cardozo.

By anyone's criteria Atkinson's atlas is a worthwhile addition to the diagnostic cytology armamentarium. In many respects it is excellent, although a slight unevenness, perhaps inevitable in any multiple author work must be acknowledged. Its text, authored by an impressive array of experts in the field, although laudably concise, is comprehensive in its breadth. It effectively covers basic information, such as the diagnostic approach to a smear, in addition to the most recent ancillary techniques, such as fluorescent in situ hybridisation and laser scanning cytometry. It is timely and useful, but unfortunate, that the breadth of coverage also extends to a discussion of medicolegal liability in the practice of cytology.

The images, central to the purpose of this work, are almost universally of high quality, both in terms of their initial acquisition and reproduction. The source of the images, the collections of the many authors, inevitably leads to some inconsistencies. I found the occasional image dark, light, "milky", or poorly focused, and rarely found an example of a picture that did not really illustrate, in my opinion, any characteristic feature of the entity it purported to represent. But for the aficionado there is plenty of lagniappe here, from beautiful images of humble observations (such as Spinnbarkeit in a cervical smear) to rare fine needle aspiration samples of follicular dendritic cell sarcoma and other unusual neoplasms.

This work, despite its imperfections, does span the utility gap between the beginner and the expert and will be useful in both large academic and small departments.

W R Geddie

\section{Diagnostic Musculoskeletal Surgical Pathology}

Edited by S E Kilpatrick, J B Renner. London: Published by Elsevier, 2003, £119.00 (hardback), pp 393. ISBN 0-7216-9163-3

This is a superb book combining radiological and pathological features and including colour illustrations of both bone and soft tissue tumours.

Entities are discussed in a clear, cogent manner. Numerous helpful tables liberally supplement the text and serve as an aide de memoir.

All illustrations are of high quality and show the reader the essential diagnostic features. The additional feature of this book is the associated fine needle aspiration findings. Although not a practicising cytopathologist, I must say that I found these to be aesthetically pleasing but would have difficulty diagnosing a myxofibrosarcoma on fine needle aspiration! Be that as it may, I am sure that aficionados of cytopathology would no doubt find the illustrations diagnostic.

All in all, there isa little, if any, fault with this book. I thoroughly recommend it as a bench book for those encountering soft tissue and bone tumours. The radiological pictures are also excellent and give the reader a handle on what to expect with the various tumours. This book compares very favourably with its larger and better known competitors. As a starting point for the diagnosis of bone and/or soft tissue tumours, I think that this is an excellent book.

R Chetty 


\section{Handbook on Proteomic Methods}

Edited by P M Conn. New Jersey: Humana Press, 2003, \$135.00 (hardback), pp 610. ISBN 1588293408

This book is a 510 page, hard cover issue covering proteomic methods and their applications in molecular biology, a subject that is of interest to many molecular scientists. It consists of four major sections, which include both colour and black and white illustrations. The first major section deals with the general techniques of proteomics and specific aspects of the technology. The second section concentrates on post-translational modifications, variants, and isoforms. Here, the characterisation of protein isoforms is discussed at length.

The book is written by a group of well recognised scientists who describe a wide range of state of the art techniques used for the identification of and analysis of a variety of proteins that are expressed in the cell.

The techniques described vary from very general to highly specific ones that are used for data analysis and the investigation of post-translational modifications. In addition, several methods describing how the application of proteomics can be used to identify new drugs and markers for cancer are also discussed. The methods for each protocol are described in great detail, together with potential trouble shooting approaches, which may be necessary when encountering problems.

This book is a well written, fully referenced text on proteomic methods, which provides an excellent guide to any scientist working in the field. In addition, the book also demonstrates how proteomic methods might provide a clearer insight into complex biological systems ranging from plants to humans in the amelioration of disease. Furthermore, this technology could provide a means for better and more effective drug development.

The editor has produced a remarkable book, which is ideal for any scientist working in the proteomics field.

R Naidoo

\section{Quinolone Antimicrobial Agents. 3rd} Ed.

Edited by D C Hooper, E Rubinstein. Washington: ASM Press, 2003, \$125.95, pp 485. ISBN 1-55581-231-7
In 1984, as a wet behind the ears house officer, I remember waiting with great anticipation for the new wonder drug ciprofloxacin to arrive by motorcycle courier so that it could be used for a patient with refractory febrile neutropenia. Nowadays, quinolones such as ciprofloxacin have become so widely used that it may be difficult for younger bacteriologists to imagine $\mathrm{BBQ}$ (bacteriology before quinolones)! The important place that these compounds have assumed in the antimicrobial pharmacopoeia is reflected by the fact that this is the third edition of this text in 10 years.

The book is divided into four sections, covering mechanisms and spectrum of antibacterial activity and resistance; pharmacology; clinical applications; and adverse and other effects. For a USA produced book, it is refreshing to see a truly international line up of contributors. Inevitably, for a work that is so broad in its outlook, it is unlikely that every chapter, particularly in the first two sections, will be consulted with equal frequency - for example, the chapter on structure-activity relations of the quinolones is unlikely to whip the jobbing clinical bacteriologist into an uncontrolled state of frenzied excitement. However, this is not to say that all of the non-clinical chapters will go unread by those with a more clinical orientationthe chapters on mechanisms of action and resistance make interesting reading. The clinical applications section accounts for 16 of the book's 30 chapters and includes chapters on the use of quinolones in the management of intra-abdominal infections and infections caused by intracellular pathogens, and the use of these drugs in intensive care unit infections and, perhaps of most interest, paediatrics; none of these areas appeared in the second edition of the book. Quinolone resistance is revisited again in this section, but there is little overlap with earlier chapters. Donald Low's excellent chapter on the clinical relevance of quinolone resistance is one of the highlights of the book, and the chapter on the impact of veterinary use of these drugs on resistance in bacterial isolates from human infection makes sobering reading, and emphasises the fact that there is still much to be done in limiting the use of these drugs in the agricultural sector.

The infamous list of quinolones withdrawn before or after reaching the market place because of serious toxicity must be the cause of many a sleepless night for some of those employed by the pharmaceutical industry, and the final section of the book considers these toxicities in detail.

Several chapters throughout the book stray a little from their remit-for example, the one which deals with QT prolongation by quinolones includes a rather too detailed discussion of electrophysiology, and the chapter on the treatment of intracellular infection focuses much of its attention on the use of other drugs, such as tetracyclines and macrolides, in this setting. I would also have liked to have seen more discussion concerning the accumulating evidence linking quinolones with the emergence of methicillin resistant Staphyloccus aureus. Nevertheless, these are relatively minor criticisms, and the book would make a valuable addition to the departmental library of any clinical microbiology laboratory.

K G Kerr

\section{CORRECTIONS}

Mouse models of childhood cancer of the nervous system. M A Dyer. J Clin Pathol 2004;57:561-76. The author apologises for the ambiguous sentence on page 573 . The sentence: "Tumours form when Rb, pl07, and p53 are inactivated, but whether p107, p53, or both genes must be inactivated for retinoblastoma to form in the mouse retina is unknown." should have read: "Tumours form when $\mathrm{Rb}, \mathrm{pl07}$, and $\mathrm{p} 53$ are inactivated, or when Rb and pl07 are inactivated. However, it is not known whether pl07, p53, or both genes must be inactivated for metastatic retinoblastoma to form in the mouse retina because all possible genetic combinations were not characterised."

The practical application of reflectance spectrophotometry for the demonstration of haemoglobin and its degradation in bruises. V K Hughes, P S Ellis, T Burt, et al. $J$ Clin Pathol 2004;57:355-9. Reference 27 is incorrect. It should have been: Edwards EA, Duntley SQ. The pigments and color of living skin. Am J Anat 1939;65:1-33. The author apologises for any inconvenience this may have caused. 